\title{
Electroporation-enhanced transdermal diclofenac sodium delivery into the knee joint in a rat model of acute arthritis
}

This article was published in the following Dove Press journal: Drug Design, Development and Therapy

\section{Petra Hartmann' \\ Edina Butt ${ }^{2}$ \\ Ágnes Fehér ${ }^{1}$ \\ Ágnes Lilla Szilágyi' \\ Kurszán Dávid Jász' \\ Boglárka Balázs ${ }^{3}$ \\ Mónika Bakonyi ${ }^{3}$ \\ Szilvia Berkó ${ }^{3}$ \\ Gábor Erős ${ }^{4}$ \\ Mihály Boros' \\ Gyöngyi Horváth ${ }^{5}$ \\ Endre Varga ${ }^{2}$ \\ Erzsébet Csányi ${ }^{3}$}

'Institute of Surgical Research, University of Szeged, Szeged, Hungary;

${ }^{2}$ Department of Traumatology,

University of Szeged, Szeged, Hungary;

${ }^{3}$ Department of Pharmaceutical

Technology, University of Szeged,

Szeged, Hungary; ${ }^{4}$ Department of

Pathology, University of Szeged, Szeged, Hungary; ${ }^{5}$ Department of Physiology, University of Szeged, Szeged, Hungary
Correspondence: Petra Hartmann Institute of Surgical Research, University of Szeged, Szőkefalvi-Nagy B. u. 6, H-6720 Szeged, Hungary

$\mathrm{Tel}+3662545103$

Fax +36 62545743

Email hartmann.petra@med.u-szeged.hu
Purpose: Since electroporation (EP) can increase the permeability of biological membranes, we hypothesized that it offers an opportunity to enhance the transdermal delivery of drugs for intra-articular indications. Our aim was to compare the anti-inflammatory and analgesic efficacy of EP-combined topical administration of diclofenac sodium hydrogel $\left(50 \mathrm{mg} \mathrm{mL}^{-1}\right.$ in $230 \mu \mathrm{L}$ volume) with that of an equivalent dose of oral $\left(75 \mathrm{mg} \mathrm{kg}^{-1}\right)$ and simple topical administration. Methods: Arthritis was induced with the injection of $2 \% \lambda$-carrageenan and $4 \%$ kaolin into the right knee joints of male Sprague Dawley rats. EP was applied for 8 min with $900 \mathrm{~V}$ highvoltage pulses for $5 \mathrm{~ms}$ followed by a $20 \mathrm{~ms}$ break. Drug penetration into the synovial fluid and plasma was detected by high-performance liquid chromatography. Leukocyte-endothelial interactions were visualized by intravital videomicroscopy on the internal surface of the synovium. Inflammation-induced thermal and mechanical hyperalgesia reactions, knee joint edema, and inflammatory enzyme activities were assessed at 24 and $48 \mathrm{~h}$ after arthritis induction.

Results: EP significantly increased the plasma level of diclofenac as compared with the topical controls $10 \mathrm{~min}$ after the $2 \% \lambda$-carrageenan and $4 \%$ kaolin injection. Increased leukocyteendothelial interactions were accompanied by joint inflammation, which was significantly reduced by oral and EP diclofenac (by $45 \%$ and by $30 \%$, respectively) and only slightly ameliorated by simple topical diclofenac treatment (by 18\%). The arthritis-related secondary hyperalgesic reactions were significantly ameliorated by oral and EP-enhanced topical diclofenac treatments. The knee crosssection area (which increased by 35\%) was also reduced with both approaches. However, simple topical application did not influence the development of joint edema and secondary hyperalgesia. Conclusion: The study provides evidence for the first time of the potent anti-inflammatory and analgesic effects of EP-enhanced topical diclofenac during arthritis. The therapeutic benefit provided by EP is comparable with that of oral diclofenac; EP is a useful alternative to conventional routes of administration.

Keywords: diclofenac, transdermal delivery, HPLC, intravital videomicroscopy

\section{Introduction}

Arthritis is a collective term encompassing many diseases with distinct etiologies but common symptoms, such as joint pain and inflammation. Owing to its high incidence, it is of significant public health and economic importance, yet therapeutic options are limited to pain relief and reduction of inflammation. ${ }^{1,2}$ Today, the "gold standard" therapy for alleviating arthritis-related pain is diclofenac, a nonsteroidal anti-inflammatory drug (NSAID) of the phenylacetic acid class. ${ }^{3,4}$

Unfortunately, the side effects of such an effective compound are also significant. Diclofenac usages are associated with the NSAID category risk of dose-related 
gastrointestinal, cardiovascular, and renal adverse effects; topical preparations were thus developed to limit the potentially serious complications of systemic treatments. Diclofenac is a lipophilic organic acid, but formulations with salts are water-soluble, and this property renders the compound capable of penetrating the skin and the synovial lining of diarthrodial joints. The systemic absorption of topically administered diclofenac is $3 \%-5 \%$ of that of oral products, and the dosage reaches the site of action ten times later as compared with that of an equivalent oral dose. ${ }^{5,6}$ On the whole, since passive transdermal passage after topical administrations is rather slow and therapeutic drug levels cannot always be reached, new delivery methods are needed to achieve locally effective drug concentrations directly at the application site. ${ }^{7}$

Various skin penetration techniques have been developed to improve transdermal drug delivery and bioavailability, including ultrasound and electroporation (EP). ${ }^{8-14}$ With EP, applications of short, high-voltage pulses cause transitory structural perturbations in the lipid bilayer of the membranes. Lipophilic or hydrophilic molecules, neutral or highly charged compounds, can thus be transported through or into membranes of bacteria or mammalian cells, if they are up to $40 \mathrm{kDa}$ in molecular weight. ${ }^{15}$ Common fields of indication for EP are biological and artificial membranes, but complex structures such as the stratum corneum or the synovium can also be targeted. ${ }^{16,17}$

Based on this background, we hypothesized that EP can amplify the transport of topical diclofenac into the joints, and thus the effectiveness of local administration increases. The aims were to compare the penetration properties of diclofenac hydrogel into the synovial fluid after different administration routes and to estimate the analgesic and anti-inflammatory reactions after oral and topical drug deliveries in a standardized rat model of carrageenan/kaolin $(\mathrm{C} / \mathrm{K})$-induced knee joint monoarthritis.

\section{Materials and methods}

The experiments were performed on male Sprague Dawley rats (average weight $300 \pm 50 \mathrm{~g}$ ). The animals were housed in plastic cages in a thermoneutral environment and provided standard laboratory chow and water ad libitum. The experimental protocol complied with EU Directive 2010/63 for the Protection of Animals Used for Scientific Purposes and was approved by Hungary's National Scientific Ethical Committee on Animal Experimentation (National Competent Authority) under license number V./148/2013. This study also satisfied the criteria in the US National Institutes of Health Guidelines for the Care and Use of Laboratory Animals.

\section{Arthritis induction}

For arthritis induction, the animals were anesthetized with intraperitoneal (IP) ketamine (50 $\mathrm{mg} \mathrm{kg}^{-1}$ ) and xylazine (12 $\mathrm{mg} \mathrm{kg}^{-1}$ ), and the skin over the knees was disinfected with povidone iodide. Then a single intra-articular injection of a $75 \mu \mathrm{L}$ mixture of $2 \% \lambda$-carrageenan (Sigma-Aldrich, St Louis, MO, USA) and $4 \%$ kaolin in saline was administered to the right knee joint. ${ }^{18,19}$ The contralateral knee was injected with saline.

\section{Experimental protocols}

The goal of the first experimental series was to assess the serum and the synovial concentrations of diclofenac by highperformance liquid chromatography (HPLC). The animals were anesthetized with IP sodium pentobarbital $\left(45 \mathrm{mg} \mathrm{kg}^{-1}\right)$ and placed in a supine position on a heating pad to maintain body temperature between $36^{\circ} \mathrm{C}$ and $37^{\circ} \mathrm{C}$. In the first group $(\mathrm{n}=16)$, diclofenac sodium gel $\left(50 \mathrm{mg} \mathrm{mL}^{-1}\right.$ in $230 \mu \mathrm{L}$ volume) was applied topically above the knee joint. In the second group $(\mathrm{n}=16)$, after dispersion of the diclofenac gel over the knee joint, EP was applied for $8 \mathrm{~min}$. Samples of blood from the inferior vena cava and of synovial washing fluid from the knee joint were collected at 10, 30, 60, and $120 \mathrm{~min}$ of the experiment. The samples were frozen at $-80^{\circ} \mathrm{C}$ until the HPLC measurement. At the end of the last sampling point, the animals were sacrificed with a single overdose of anesthetic (Figure 1).

In the second series of experiments, inflammation-related changes to the synovial microcirculation were evaluated directly by intravital videomicroscopy (IVM). The animals were anesthetized with IP sodium pentobarbital ( $\left.45 \mathrm{mg} \mathrm{kg}^{-1}\right)$ and divided into four groups according to the administration route of diclofenac: The animals were treated with per os diclofenac $\left(75 \mathrm{mg} \mathrm{kg}^{-1}\right.$ diclofenac sodium, Novartis Hungaria Kft., Budapest, Hungary) in Group $1(\mathrm{n}=6)$, with topical diclofenac gel $\left(50 \mathrm{mg} \mathrm{mL}^{-1}\right.$ in $230 \mu \mathrm{L}$ volume; $\mathrm{n}=6$ ) in Group 2, and with EP-combined topical diclofenac gel (50 $\mathrm{mg} \mathrm{mL}^{-1}$ in $230 \mu \mathrm{L}$ volume; $\mathrm{n}=6$ ) in Group 3. Group 4 served as a per os saline-treated control $(n=6)$. The treatments were always applied $2 \mathrm{~h}$ before $(t=-2 \mathrm{~h})$ and $2 \mathrm{~h}$ after $(t=2 \mathrm{~h})$ the arthritis induction (Figure 1).

In the third experimental series, the effectiveness of different routes of diclofenac treatment on nociception and inflammatory edema formation was compared in $\mathrm{C} / \mathrm{K}$-induced arthritis. The animals were divided into four groups ( $n=6)$ according to the administration route of diclofenac: 1) per os diclofenac sodium, 2) topical diclofenac gel, 3) EP-enhanced topical diclofenac gel, and 4) sham 

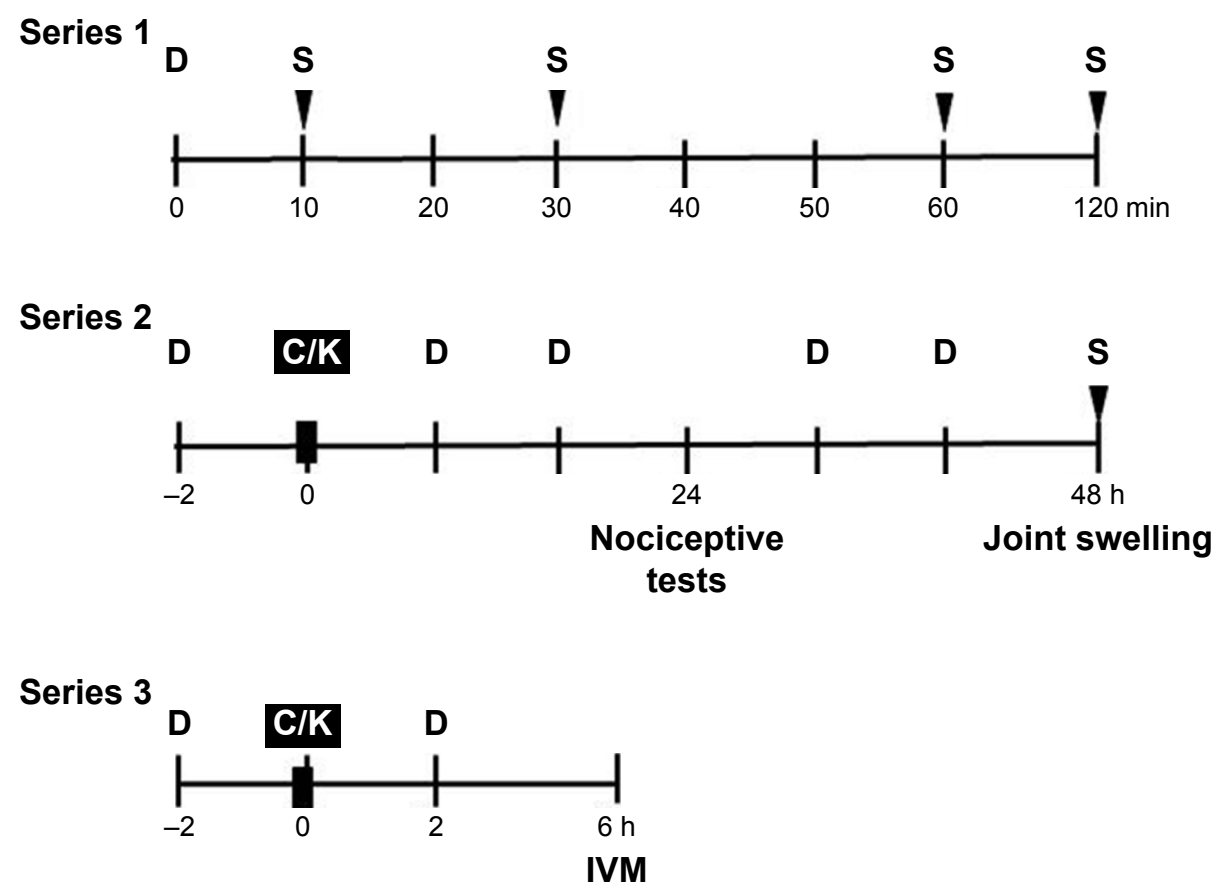

Figure I Time sequence of interventions.

Notes: In the first series, the diclofenac concentration in the serum and the synovial washing fluid was measured by HPLC. In the second experimental series, tests for secondary mechanical touch sensitivity and heat-provoked paw withdrawal were performed $24 \mathrm{~h}$ after arthritis induction with C/K and for knee joint swelling measurements $48 \mathrm{~h}$ after the challenge. In the third series, IVM examinations of the synovial membrane were performed $6 \mathrm{~h}$ after the challenge.

Abbreviations: C/K, carrageenan/kaolin; D, diclofenac treatment; HPLC, high-performance liquid chromatography; IVM, intravital videomicroscopy; S, sample taken.

(per os saline-treated). Treatments were applied twice daily (every $12 \mathrm{~h}$ ). The nociceptive tests were performed $24 \mathrm{~h}$ after the $\mathrm{C} / \mathrm{K}$ injection, while knee joint swelling was evaluated at the peak of edema formation $48 \mathrm{~h}$ after arthritis induction. At the end of the experiments, the animals were anesthetized with IP sodium pentobarbital $\left(45 \mathrm{mg} \mathrm{kg}^{-1}\right)$ for sample taking and thereafter sacrificed with a single overdose of anesthetic. Synovial washing fluid samples and synovium tissue specimens were collected for biochemical measurements and histology. Tissue biopsies were stored at $-20^{\circ} \mathrm{C}$ until the examinations (Figure 1).

\section{Diclofenac-containing hydrogel formulation}

The hydrogel was prepared using the following procedure. Five $\mathrm{w} / \mathrm{w} \%$ diclofenac sodium (Sigma-Aldrich) was dissolved in a mixture of purified water and $30 \mathrm{w} / \mathrm{w} \%$ ethanol (Sigma-Aldrich). Two w/w\% hydroxypropyl methylcellulose (METHOCEL E4M Premium, Dow Chemical, Midland, MI, USA) was added to this solution. The $\mathrm{pH}$ value was adjusted to $8.0 \pm 0.1$ to ensure the dissolution of the active substance by adding triethanolamine $(2 \mathrm{w} / \mathrm{w} \%$ solution, Hungaropharma Ltd., Budapest, Hungary) if necessary (Supplementary materials).

\section{Electroporation protocols}

The noninvasive skin EP treatment was performed with a Mezoforte Duo Mez 120905-D instrument (Dr Derm Equipment Ltd., Budapest, Hungary). A polypropylenecovered treating handpiece with a $25 \mathrm{~mm}$ diameter plate electrode was used (modulation with $900 \mathrm{~V}$ pulses, a $5 \mathrm{~ms}$ voltage pulse was followed by a $20 \mathrm{~ms}$ break). Two hundred thirty $\mu \mathrm{L}$ diclofenac hydrogel was used, and the EP treatment time was $8 \mathrm{~min}$.

\section{HPLC measurements}

The synovial washing fluid and plasma samples were analyzed using an Agilent HPLC system (Agilent Technologies, Palo Alto, CA, USA) equipped with an automated solvent delivery system, which has an integrated degasser (1260 Infinity Quaternary Pump, Agilent Technologies), an Agilent 1260 Infinity autosampler (Agilent Technologies) and a 1024-element diode array detector (1260 Infinity Diode Array Detector, Agilent Technologies). The system control and data acquisition were performed with Agilent ChemStation B.04.03 software (Agilent Technologies). The chromatographic parameters and the sample extraction procedure have been provided in the Supplementary materials. 


\section{Nociceptive tests}

Mechanical hyperalgesia was quantified using a plantar aesthesiometer (Dynamic Plantar Aesthesiometer mod-37450; UgoBasile, Comerio, Italy) and was expressed as paw withdrawal thresholds. Thermal hyperalgesia was detected with the paw withdrawal test using a Hargreaves apparatus..$^{20}$ Baseline measurements were performed before the induction of arthritis, while the development of inflammation was investigated at the peak of nociceptive sensitivity $24 \mathrm{~h}$ after $\mathrm{C} / \mathrm{K}$ injection.

\section{Knee joint swelling (morphological assessment)}

Joint inflammation was characterized by the changes in the diameter of the joints $48 \mathrm{~h}$ after $\mathrm{C} / \mathrm{K}$ injection. The anteroposterior and mediolateral diameters were measured with a caliper square, and the cross-sectional area was calculated.

\section{Analysis of gastric effects}

Gastric lesions potentially associated with diclofenac toxicity were assessed at $48 \mathrm{~h}$. After retrieving and washing with saline, photographs were taken of the freshly prepared stomachs. The location (near the pylorus, lesser curvature of the fundus, or diffuse) was recorded, and the extent of the lesions was evaluated by planimetric analysis using the ImageJ software (National Institutes of Health, Bethesda, MD, USA).

\section{Synovial sampling}

The skin over the knee was disinfected with povidone iodide, and $75 \mu \mathrm{L}$ PBS was injected into the knee to collect synovial fluid. The fluid was centrifuged at $4^{\circ} \mathrm{C}$ for 5 min at $4,000 \mathrm{~g}$ in Eppendorf tubes. Then the samples were frozen at $-80^{\circ} \mathrm{C}$ until they could be tested.

\section{TNF- $\alpha$ levels}

The cytokine content of the synovial washing fluid was measured with commercially available enzyme-linked immunosorbent assay kits (Quantikine Ultrasensitive ELISA kit; Biomedica Hungaria Ltd., Budapest, Hungary).

\section{MPO activity}

Tissue MPO activity was measured in synovium and periosteum biopsies using the method developed by Kuebler et al. ${ }^{21}$ Briefly, the tissue was homogenized with Tris- $\mathrm{HCl}$ buffer (0.1 M, pH 7.4) containing $0.1 \mathrm{M}$ polymethylsulfonyl fluoride to block tissue proteases and then centrifuged at $4{ }^{\circ} \mathrm{C}$ for $20 \mathrm{~min}$ at $24,000 \mathrm{~g}$. The MPO activities of the samples were measured at $450 \mathrm{~nm}$ (UV-1601 spectrophotometer;
Shimadzu, Kyoto, Japan), and the data were corrected for the protein content.

\section{XOR activity}

Tissue biopsies were homogenized in a phosphate buffer (pH 7.4) containing $50 \mathrm{mM}$ Tris-HCl, $0.1 \mathrm{mM}$ EDTA, $0.5 \mathrm{mM}$ dithiotreitol, $1 \mathrm{mM}$ phenylmethylsulfonyl fluoride, $10 \mu \mathrm{g} \mathrm{mL}^{-1}$ soybean trypsin inhibitor, and $10 \mu \mathrm{g} \mathrm{mL} \mathrm{m}^{-1}$ leupeptin. The homogenate was centrifuged at $4^{\circ} \mathrm{C}$ for $20 \mathrm{~min}$ at $24,000 \mathrm{~g}$, and the supernatant was loaded into centrifugal concentrator tubes. The activity of XOR was determined in the ultrafiltered supernatant by fluorometric kinetic assay based on the conversion of pterine to isoxanthopterine in the presence (total XOR) or absence (XOR activity) of the electron acceptor methylene blue. ${ }^{22}$

\section{Surgical procedure for the IVM examinations}

A detailed description of the surgical procedure can be found elsewhere. In brief, the animals were anesthetized with IP sodium pentobarbital $\left(45 \mathrm{mg} \mathrm{kg}^{-1}\right) 6 \mathrm{~h}$ after the intra-articular $\mathrm{C} / \mathrm{K}$ injection. ${ }^{23}$ The jugular vein was cannulated for further supplementary doses of anesthetic. Cannulation of the trachea maintained the patent airway, and the arterial pressure was monitored through a carotid artery cannule (Statham P23Db transducer; Experimetria Ltd., Budapest, Hungary). The animals were placed on a specially designed heating pad in a supine position for the IVM examination, during which the slightly flexed knee joint of the hind limb was opened with a microsurgical technique. Surgical preparation included a longitudinal skin incision and a transverse cut of the quadriceps femoris tendon. After a circumferential cut on the joint capsule, the patella was turned aside, and the synovial membrane on the medial condyle of the tibia was visible.

\section{IVM examinations}

Synovial microcirculation was investigated by means of fluorescent IVM (Zeiss Axiotech Vario 100 HD microscope, 100 W HBO mercury lamp, Acroplan 20× water immersion objective), while the synovial membrane was superfused with $37^{\circ} \mathrm{C}$ saline. Erythrocytes were labeled with fluorescent isothiocyanate $(0.2 \mathrm{~mL}$ intravenously, Sigma-Aldrich Chemicals) and leukocytes were stained with rhodamine-6G (0.1 mL intravenously, Sigma-Aldrich).

\section{Video analysis}

IVM records were analyzed offline and frame-to-frame using image analysis software (IVM, Pictron Ltd., Budapest, 
Hungary). Polymorphonuclear leukocytes (PMNs) were defined as cells adherent (stickers) to the endothelial lining within an observation period of $30 \mathrm{~s}$. The number of adherent cells per $\mathrm{mm}^{2}$ of endothelial surface was counted in 5 postcapillary venules (diameter ranges from 11 to $15 \mu \mathrm{m}$ ) per animal.

\section{Statistical analysis}

Data analysis was performed with the SPSS 17.0 software (SPSS Inc., Chicago, IL, USA). Changes in variables within and between groups were analyzed by two-way analysis of variance, followed by the Holm-Sidak test. All data are expressed as means \pm standard deviation of the mean. $P$-values $<0.05$ were considered statistically significant.

\section{Results}

\section{Plasma and synovial diclofenac concentrations}

The plasma and the serum concentrations of diclofenac were the highest $10 \mathrm{~min}$ after the EP treatment; they then decreased at $30 \mathrm{~min}$ and remained constant at 60 and $120 \mathrm{~min}$. EP-enhanced diclofenac delivery exhibited a significantly higher plasma level of diclofenac as compared with the simple topical application $10 \mathrm{~min}$ after the application (Figure 2). There were no significant differences in the diclofenac content of the synovial fluid and the plasma after the EP-combined application. However, simple topical application did not result in detectable diclofenac content in the synovial fluid at the same point in time (Figure 2).

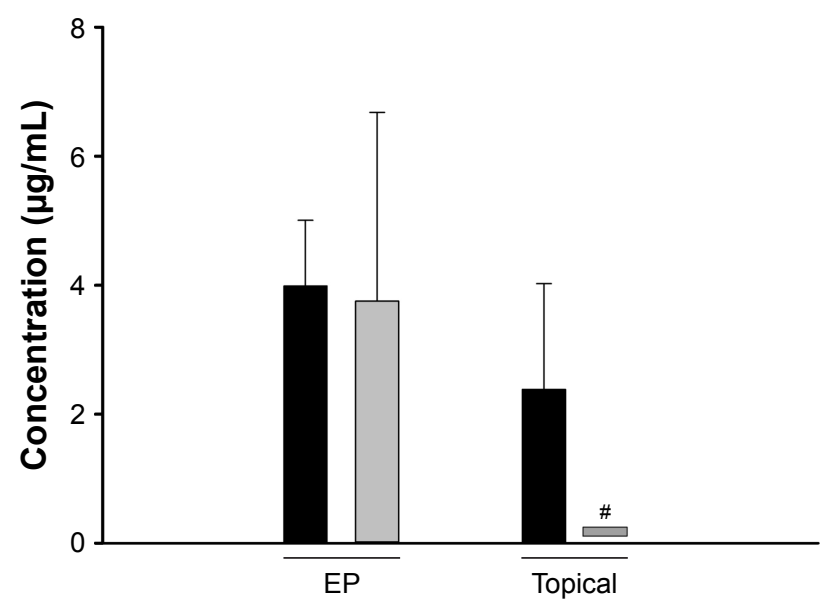

Figure 2 Diclofenac concentrations in the serum (black columns) and the synovial washing fluid (gray columns) measured by HPLC (Series I).

Notes: Diclofenac sodium gel was applied topically above the knee joint (topical), or EP was applied for 8 min over the knee joint (EP) after the diclofenac gel dispersed. Samples of blood and synovial washing fluid were collected 10 min after application. Data are presented as means \pm SD. ${ }^{\#} p<0.05$ vs serum level (two-way ANOVA and Holm-Sidak test).

Abbreviations: ANOVA, analysis of variance; EP, electroporation; HPLC, highperformance liquid chromatography; SD, standard deviation of the mean.

\section{Leukocyte-endothelial interactions}

In the second experimental series, the microcirculatory consequences of the joint inflammation were quantified via IVM, and the PMN-endothelial interactions (rolling and sticking) in the postcapillary venules of the synovial membrane were determined. The rolling fraction of the PMNs in the postcapillary synovial venules exhibited a large degree of dispersion, and no baseline differences were observed between the $\mathrm{C} / \mathrm{K}$ - and saline-injected knees or between the groups which participated in the treatment protocols (data not shown). However, the injection of $\mathrm{C} / \mathrm{K}$ was accompanied by a statistically significant increase in PMN adherence (sticking) to the endothelial layer as compared to the control side (Figure 3). This reaction was considerably reduced with the administration of oral diclofenac. However, it was only moderately ameliorated by the EP-enhanced diclofenac hydrogel, and there were no changes in response to the simple topical application of the hydrogel.

\section{Inflammatory enzyme activities and cytokine production}

XOR activity was significantly increased in response to arthritis induction, in comparison with the saline-injected knee joint. These values were significantly decreased when diclofenac was applied orally or topically (Figure 4A).

In the $\mathrm{C} / \mathrm{K}$-injected limbs, the MPO activity of the synovial tissue was significantly increased as compared with that of the saline-injected controls. In the oral diclofenac and EP-enhanced topical diclofenac-treated groups, MPO activity was significantly lower than in the nontreated animals. However, conventional topical treatment did not influence the increased MPO activity (Figure 4B).

The $\mathrm{C} / \mathrm{K}$ injection resulted in a significant increase in TNF- $\alpha$ concentration in the synovial lavage fluid, which was diminished by both the oral intake and EP-enhanced topical treatment (Figure 4C).

\section{Nociception and inflammatory edema}

In the third series, the extent of inflammation was estimated with functional tests $24 \mathrm{~h}$ after arthritis induction. The mechanical touch sensitivity was considerably increased in response to arthritis as the $\mathrm{C} / \mathrm{K}$-injected limbs responded to a lower level of trigger than the saline-injected control limbs in animals receiving the saline vehicle (Figure 5A). This parameter was significantly diminished in response to oral and EP-enhanced topical diclofenac treatments, albeit that complete restoration was not achieved. The thermal nociceptive latency (Figure 5B) was also significantly decreased 

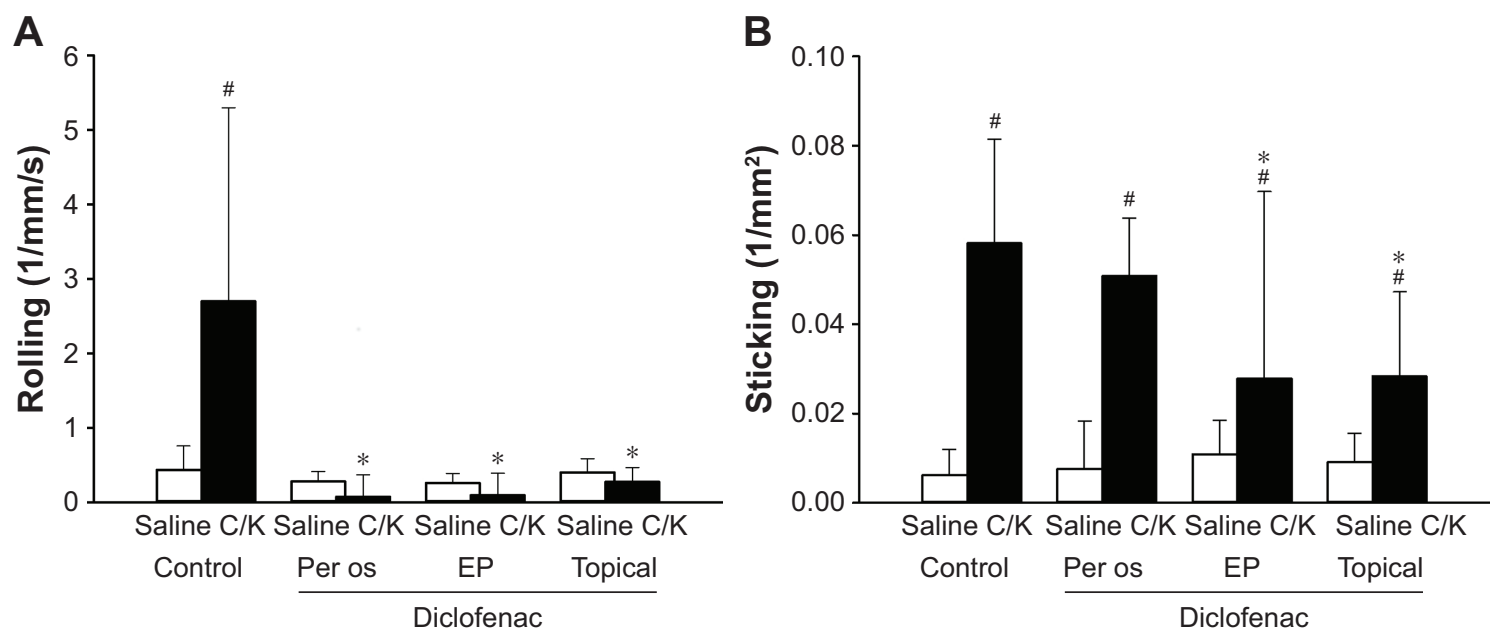

Figure 3 The effects of diclofenac treatments on the number of rolling $(\mathbf{A})$ and sticking (B) leukocytes in the postcapillary venules of the synovial membrane (Series 3 ).

Notes: Knees were injected with $\mathrm{C} / \mathrm{K}$ (black columns), or contralateral knees were treated with a saline vehicle (white columns). Data are presented as means \pm SD. $\#<0.05$ vs control limb; ${ }^{*} p<0.05$ vs $\mathrm{C} / \mathrm{K}+$ oral saline (two-way ANOVA and Holm-Sidak test).

Abbreviations: ANOVA, analysis of variance; C/K, carrageenan/kaolin; SD, standard deviation of the mean.
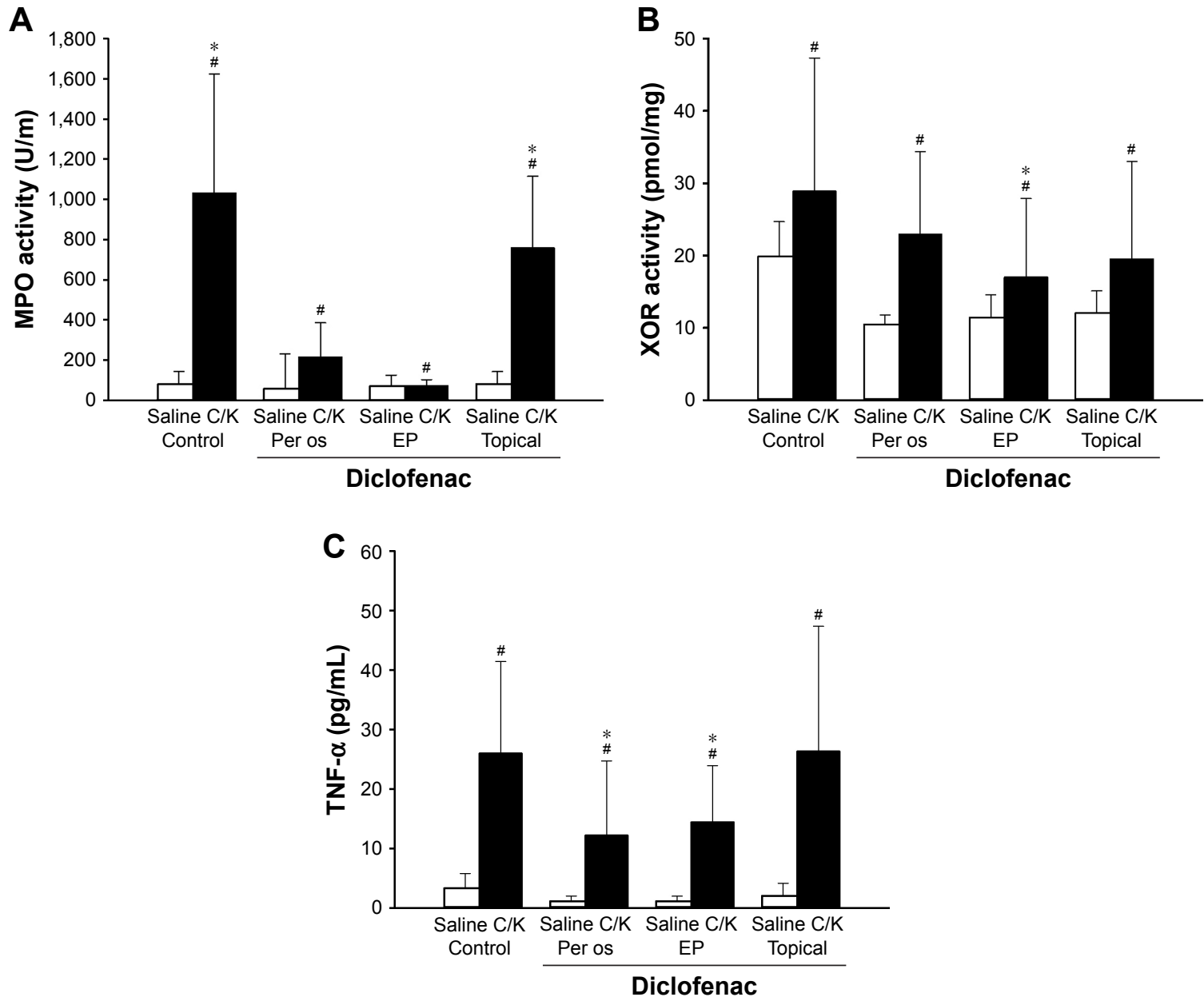

Figure 4 The effects of diclofenac treatments on the C/K-induced changes in MPO activity (A), XOR activity (B), and TNF- $\alpha$ levels (C) (Series 2).

Notes: Knees were injected with $\mathrm{C} / \mathrm{K}$ (black columns), or contralateral knees were treated with a saline vehicle (white columns). Data are presented as means \pm SD. ${ }^{\#}<<0.05$ vs control limb; $* p<0.05$ vs $\mathrm{C} / \mathrm{K}+$ oral saline (two-way ANOVA and Holm-Sidak test).

Abbreviations: ANOVA, analysis of variance; C/K, carrageenan/kaolin; SD, standard deviation of the mean. 

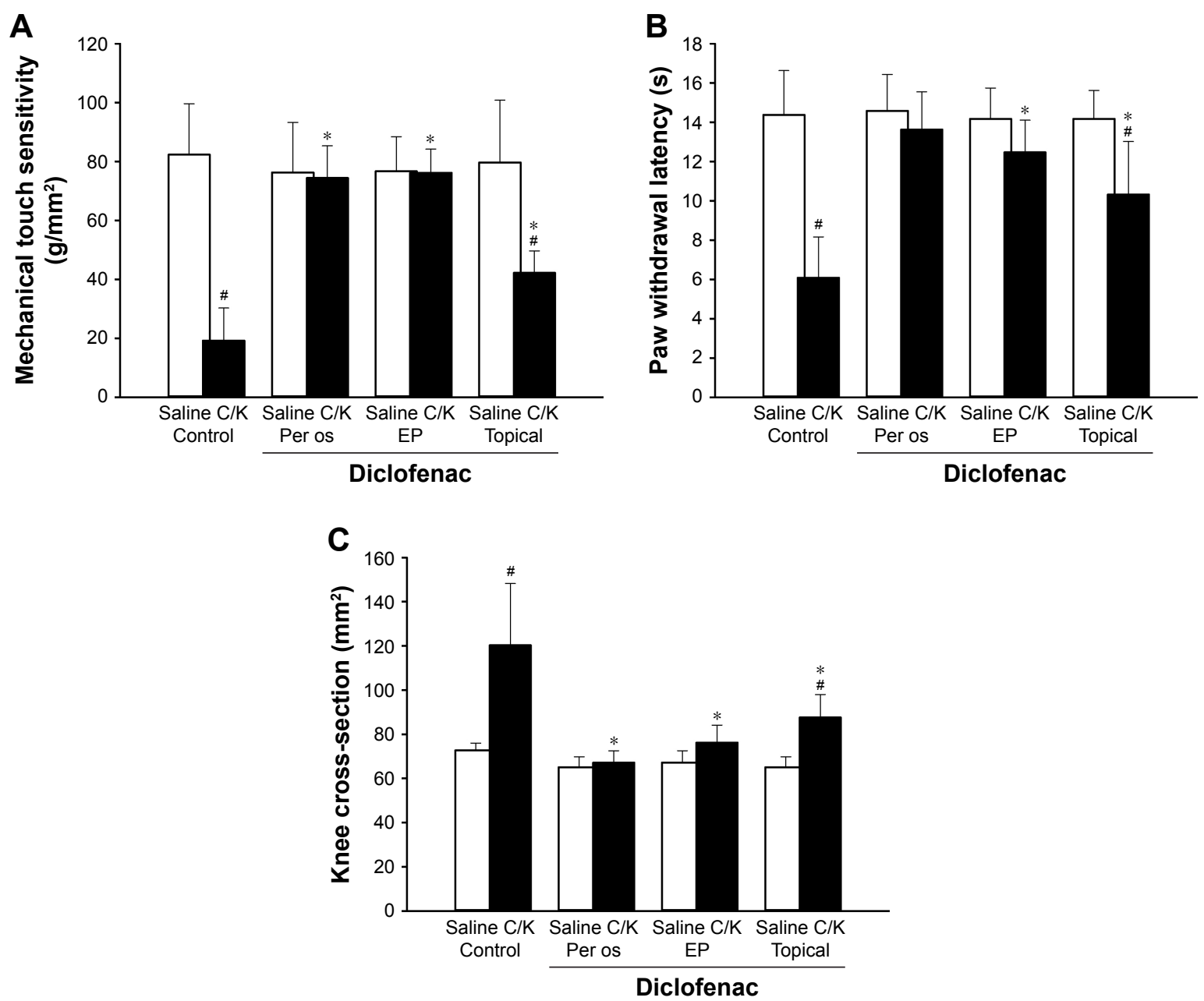

Figure 5 The effects of diclofenac treatments on the C/K-induced changes in mechanical touch sensitivity (A), heat-provoked paw withdrawal latency (B), and changes in knee joint swelling (C) (expressed as a knee cross-section) (Series 2).

Notes: Knees were injected with $C / K$ (black columns), or contralateral knees were treated with a saline vehicle (white columns). Data are presented as means \pm SD. $\#<<0.05$ vs control limb; ${ }^{*} p<0.05$ vs $C / K+$ oral saline (two-way ANOVA and Holm-Sidak test).

Abbreviations: ANOVA, analysis of variance; C/K, carrageenan/kaolin; SD, standard deviation of the mean.

in the injured leg in the saline-treated group, and oral and EP-enhanced topical diclofenac treatments exerted similar protective effects to those seen with the von Frey test.

The changes in knee cross-section (Figure 5C) furnish a direct and objective measure of joint inflammation. The cross-sectional area in the $\mathrm{C} / \mathrm{K}$-injected knees was significantly enlarged $48 \mathrm{~h}$ after the challenge but was significantly reduced by both the conventional topical and the EP-enhanced topical diclofenac treatments. In the case of oral diclofenac administration, complete restoration to the level for the saline-injected knees was achieved.

\section{Adverse effects of diclofenac intake}

The gastric adverse effects of diclofenac intake were assessed by planimetric analysis of ulcers in the gastric mucosa. The topically applied diclofenac sodium with or without EP had no deleterious effect on gastric mucosa; however, an equivalent dose of oral diclofenac sodium resulted in ulcer formation in $70 \%$ of the animals. The location of gastric ulcerations in the rat stomach was variable and included only mild lesions with edema, irritation, and petechia formation (Supplementary materials; Figure S1).

\section{Discussion}

This study has demonstrated the added value of EP to the transdermal delivery of diclofenac into the knee joint in experimental arthritis. The analgesic effect of EP-enhanced delivery was comparable to that of the oral administration and manifested in decreased nociceptive sensitivity, reduced joint swelling, and lower cytokine concentration in the synovial fluid and lower inflammatory enzyme activities in the synovial tissue. The EP treatment also influenced the number 
of PMN-endothelial interactions at the level of the synovial microcirculation.

Following oral administration, diclofenac absorbs rapidly through the gastrointestinal tract. However, due to first-pass metabolism, only $60 \%$ of the dose reaches the systemic circulation, where it bonds extensively to plasma proteins, mainly albumin. ${ }^{24}$ Substantial concentration of the drug is attained in synovial fluid, which may be one of the sites of action of diclofenac. It has been shown that the antinociceptive and anti-inflammatory action of diclofenac is directly proportional to its concentration in the synovial fluid. ${ }^{25}$ Diclofenac has a short biological half-life (approx $2 \mathrm{~h}$ ) and is eliminated following biotransformation to glucuroconjugated and sulfate metabolites, which are excreted in urine. ${ }^{26}$ The pharmacological action of oral drugs depends on the absorption into the circulation and subsequent distribution to the peripheral tissues; in contrast, efficacy of topical drugs relies on penetration through the skin.

EP is promising among skin penetration enhancement techniques; apart from transdermal delivery, application of EP has been widely investigated in cell biology, biotechnology, and electrochemotherapy. ${ }^{13,14,16}$ EP applies high-voltage pulses to the biological membranes and results in conformation changes in their stereo structures. Transdermal drug penetration into the joint cavity is mostly limited by the low permeability of the stratum corneum of the skin, the thickness of the surrounding tissue layer, and the special physicochemical barrier function of the synovial membrane, which is commonly referred to as the "blood-joint barrier."27 However, EP is capable of opening transitory pores on complex structures, such as the multilamellar lipid bilayer of the stratum corneum and the synovial membrane. ${ }^{28,29}$ Macromolecules of up to $40 \mathrm{kDa}$ can thus be transported through and/or into the skin. ${ }^{11,15}$

Electroporation is now widely used as an alternative to small interfering RNA or naked DNA delivery for targeted suppression of therapeutic genes into the knee joint in arthritis. ${ }^{30,31}$ However, electrotransfer of painkiller drugs into the knee joint is less widespread. ${ }^{32}$ According to a recent review, plasma levels of diclofenac after topical administration decrease from $0.2 \%$ to $8 \%$ of those after oral administration. ${ }^{33}$ Unfortunately, the resultant synovial concentration is also decreased, as compared to an equivalent oral dose. Effective concentrations in target tissues can be augmented with EP. ${ }^{32}$ In accordance with literature data, our results revealed that EP causes higher concentration values in the serum as compared with the topical administration. The diclofenac concentration in the synovia was equal to the serum concentrations; however, conventional topical treatment did not result in a detectable amount of diclofenac sodium in the synovial fluid.

Intra-articular injection of $\mathrm{C} / \mathrm{K}$ is a well-established model of an acute onset monoarthritis resembling osteoarthritis. In this model, arthritis is probably initiated by mechanical damage to the inner surface of the synovium resulting in an inflammatory response indirectly to the activation of the endothelial side of the synovial barrier. It is characterized by an initial nonphagocytic edema and rapid uptake of the late phagocytic inflammatory phase, where PMNs accumulate in the affected area. ${ }^{19,34}$ It has been demonstrated that PMNs are primed within $1 \mathrm{~h}$ and are in the majority up to $12 \mathrm{~h}$ after the arthritis induction; subsequently, they are replaced by predominating macrophages until the resolution of the inflammation at 48 h. ${ }^{27}$ It has also been found that the rate of PMN infiltration is directly related to severity of inflammation in the synovial membrane. ${ }^{35,36}$ Based on the pivotal role of PMNs in the initiation and maintenance of joint disorders, we employed the PMN-derived experimental model of inflammatory arthritis in these studies.

Adhesive cell-to-cell interactions are regulated by $\beta 2$ integrins (CD11/CD18) expressed on PMNs and their associated endothelial ligands (ICAMs and VCAMs). ${ }^{37}$ The presence of adhesion molecules on postcapillary endothelial cells in the inflammatory synovial microenvironment has previously been shown and proven to be an appropriate marker for estimating inflammation..$^{23,38,39}$ These reactions can be quantitatively assessed by IVM, and the efficacy of various therapeutic interventions can also be judged objectively. PMN accumulation peaks very early, usually at $6-8 \mathrm{~h}$ in this model, and (at approx $24 \mathrm{~h}$ ) macrophages predominate in the exudates thereafter. ${ }^{40}$ Like other nonselective cyclooxygenase inhibitors, diclofenac diminishes the number of PMN-endothelial interactions. ${ }^{41,42}$ Sticking in the synovial vessels was considerably reduced with the oral administration of diclofenac. However, it was only moderately ameliorated by the EP-enhanced diclofenac hydrogel, and there were no changes in response to the simple topical application of the hydrogel.

Administration of $\mathrm{C} / \mathrm{K}$ injection into the knee joint results in primary and secondary hyperalgesia in the inflammatory monoarthritis. ${ }^{43}$ Secondary hyperalgesia develops at the paw to heat and mechanical stimuli, and primary hyperalgesia is present over the inflamed knee joint. ${ }^{44,45}$ Secondary hyperalgesia develops as a result of the sensitization of the dorsal horn neurons neighboring the spinal representation of the injured tissue. ${ }^{46}$ Secondary hyperalgesia reactions 
were investigated at the peak of the joint inflammation and demonstrated a significant amelioration as a consequence of diclofenac treatment. ${ }^{47}$ Like the oral diclofenac treatment, EP completely restored thermal nociceptive sensitivity and increased mechanical touch sensitivity, but to a lesser extent. Knee swelling, which is an objective parameter of joint inflammation, was significantly reduced with both the oral and the EP-enhanced diclofenac treatment. ${ }^{48}$ Again, this increased volume was significantly reduced by both oral and EP-enhanced diclofenac treatments $48 \mathrm{~h}$ after arthritis induction.

The $\mathrm{C} / \mathrm{K}$-induced arthritis is also an appropriate model for the evaluation of the analgesic and anti-inflammatory properties of diclofenac. The TNF- $\alpha$ response is an early marker in carrageenan-induced inflammation, and thus the changes were measured in the synovial fluid $48 \mathrm{~h}$ after intra-articular $\mathrm{C} / \mathrm{K}$ or saline injections. Free radical formation has been demonstrated in the synovial fluid and synovial membrane under clinical conditions and proposed as a causative factor in joint disorders. ${ }^{22,49}$ Specifically, oxidoreductive stress has been shown to play a fundamental role in the pathogenesis of arthrosis as a result of increased pressure in the synovial cavity, reduced capillary density and vascular changes, and due to the increased metabolic rate of synovial tissue in joint inflammation. ${ }^{50-52}$ Being a source of the oxygen free radical formation located in synovial cells, XOR activity has been shown to increase in joint inflammation. ${ }^{36,53}$ Moreover, joint inflammation was also associated with enhanced XOR activity in the synovial fluid. ${ }^{54}$ Our present findings demonstrated increases in XOR activity in response to arthritis attenuated by diclofenac treatment, applied either by oral or simple topical routes of administration, the latter being more accentuated in the case of EP. PMNs are also important sources of free radicals through their NADPH oxidase 2 activities ${ }^{55}$ As for microcirculatory inflammatory reactions induced by inflammation, the increase in both the primary and secondary forms of PMN-endothelial interactions (rolling and firm adherence) were confined to the periosteal postcapillary venules. In this model, $\mathrm{C} / \mathrm{K}$-induced monoarthritis was the positive control. This aggressive arthritis model, which is associated with severe tissue destruction, is also known to be mediated by infiltrating PMNs. ${ }^{19,23}$ Data regarding the final step of PMN-endothelial interactions (ie, sticking) were well correlated with the tissue accumulation of PMNs, as determined by MPO activity. Diclofenac treatment attenuated the MPO activity in the inflamed synovial tissue, applied either via oral or EP-enhanced topical routes of administration.
The present study has provided evidence for the direct action of EP-enhanced transdermal diclofenac sodium delivery on the synovial microcirculation as proven by the decreased rolling and the reduced sticking of leukocytes. The biochemical measurements also demonstrated that diclofenac achieved an efficient tissue concentration in the synovium since inflammatory enzyme activities decreased. In summary, EP-enhanced transdermal diclofenac sodium delivery attenuated the microcirculatory deterioration and the consecutive stages of tissue inflammation; therefore, this type of mechanism might be an interesting focus for therapeutic strategies in arthritis.

\section{Conclusion}

EP-enhanced diclofenac delivery is well tolerated and possesses superior efficacy compared to simple topical application in experimental arthritis. The plasma and the joint concentrations of EP diclofenac are similar to those in oral administration. Further investigations are needed to determine the optimal parameters of EP and to diminish the plasma level of diclofenac.

\section{Acknowledgments}

The authors would like to thank Dr Derm Clinic of Antiaging Dermatology, Aesthetic Laser and Plastic Surgery (1026 Budapest, Hungary) for providing the Mezoforte Duo Mez120905-D instrument. The study was supported by grants from the National Research Development and Innovation Office (NKFI K120232) and Economic Development and Innovation Operational Program (GINOP-2 .3.2-15-2016-00015). PH and EB contributed equally to this study.

\section{Disclosure}

The authors report no conflicts of interest in this work.

\section{References}

1. Reginster JY. The prevalence and burden of arthritis. Rheumatology (Oxford). 2002;41(Suppl 1):3-6.

2. Helmick CG, Felson DT, Lawrence RC, et al. Estimates of the prevalence of arthritis and other rheumatic conditions in the United States. Part I. Arthritis Rheum. 2008;58(1):15-25.

3. Peterson K, McDonagh M, Thakurta S, et al. Drug class review: nonsteroidal anti inflammatory drugs (NSAIDs). Final update 4 report. Portland (OR): Oregon Health \& Science University; 2010.

4. Pavelka K. A comparison of the therapeutic efficacy of diclofenac in osteoarthritis: a systematic review of randomised controlled trials. Curr Med Res Opin. 2012;28(1):163-178.

5. Brunner M, Dehghanyar P, Seigfried B, Martin W, Menke G, Muller M. Favourable dermal penetration of diclofenac after administration to the skin using a novel spray gel formulation. Br J Clin Pharmacol. 2005; 60(5):573-577. 
6. Heyneman CA, Lawless-Liday C, Wall GC. Oral versus topical NSAIDs in rheumatic diseases: a comparison. Drugs. 2000;60(3):555-574.

7. Denet AR, Préat V. Transdermal delivery of timolol by electroporation through human skin. J Control Release. 2003;88(2):253-262.

8. Tachibana K. Transdermal delivery of insulin to alloxan-diabetc rabbits by ultrasound exposure. Pharm Res. 1992;9(7):952-954.

9. Bommannan D, Okuyama H, Stauffer P, Guy RH. Sonophoresis. I. The use of high-frequency ultrasound to enhance transdermal drug delivery. Pharm Res. 1992;9(4):559-564.

10. Prausnitz MR, Bose V, Langer R, Weaver JC. Electroporation of mammalian skin: A mechanism to enhance transdermal drug delivery. Proc Natl Acad Sci U S A. 1993;90(22):10504-10508.

11. Vanbever R, Lecouturier N, Préat V. Transdermal delivery of metoprolol by electroporation. Pharm Res. 1994;11(11):1657-1662.

12. Riviere JE, Monteiro-Riviere NA, Rogers RA, et al. Pulsatile transdermal delivery of LHRH using electroporation: drug delivery and skin toxicology. J Control Release. 1995;36(3):229-233.

13. Mir L, Orlowski S. Mechanisms of electrochemotherapy. Adv Drug Deliv Rev. 1999;35(1):107-118.

14. Heller R, Gilbert R, Jaroszeski MJ. Clinical applications of electrochemotherapy. Adv Drug Deliv Rev. 1999;35(1):119-129.

15. Lombry C, Dujardin N, Préat V. Transdermal delivery of macromolecules using skin electroporation. Pharm Res. 2000;17(1):32-37.

16. Weaver JC, Chizmadzhev YA. Theory of electroporation: a review. Bioelectrochem Bioenerg. 1996;41(2):135-160.

17. Denet A, Vanbever R, Préat V. Skin electroporation for transdermal and topical delivery. Adv Drug Deliv Rev. 2004;56(5):659-674.

18. Khajuria DK, Razdan R, Mahapatra DR. Description of a new method of ovariectomy in female rats. Rev Bras Reumatol. 2012; 52(3):462-470.

19. Day SM, Lockhart JC, Ferrell WR, McLean JS. Divergent roles of nitrergic and prostanoid pathways in chronic joint inflammation. Ann Rheum Dis. 2004;63(12):1564-1570.

20. Hargreaves K, Dubner R, Brown F, Flores C, Joris J. A new and sensitive method for measuring thermal nociception in cutaneous hyperalgesia. Pain. 1998;32(1):77-88.

21. Kuebler WM, Abels C, Schuerer L, Goetz AE. Measurement of neutrophil content in brain and lung tissue by a modified myeloperoxidase assay. Int J Microcirc Clin Exp. 1996;16(2):89-97.

22. Beckman JS, Parks DA, Pearson JD, Marshall PA, Freeman BA. A sensitive fluorometric assay for measuring xanthine dehydrogenase and oxidase in tissues. Free Radic Biol Med. 1989;6(6):607-615.

23. Hartmann P, Szabó A, Eros G, et al. Anti-inflammatory effects of phosphatidylcholine in neutrophil leukocyte-dependent acute arthritis in rats. Eur J Pharmacol. 2009;622(1-3):58-64.

24. Todd PA, Sorkin EM. Diclofenac sodium. A reappraisal of its pharmacodynamic and pharmacokinetic properties, and therapeutic efficacy. Drugs. 1988;35(3):244-285.

25. Vetter G. A comparison of naproxen and diclofenac sodium in the treatment of osteoarthritis in elderly patients. Br J Clin Pract. 1985; 39(7):276-281.

26. Davies NM, Anderson KE. Clinical pharmacokinetics of diclofenac. Therapeutic insights and pitfalls. Clin Pharmacokinet. 1997;33(3): 184-213.

27. Day RO, McLachlan AJ, Graham GG, Williams KM. Pharmacokinetics of nonsteroidal anti-inflammatory drugs in synovial fluid. Clin Pharmacokinet. 1999;36(3):191-210.

28. Nishimura T, Akimoto M, Miyazaki M, Nomoto M, Miyakawa M. Developments of transdermal transport system during skin iontophoresis and electroporation. PIERS Online. 2010;6(8):759-763.

29. Blagus T, Markelc B, Cemazar M, et al. In vivo real time monitoring system of electroporation mediated control of transdermal and topical drug delivery. J Control Release. 2013;172(3):862-871.

30. Zhen S, Heyong Y, Xiaoming Y, et al. Inhibition of osteoarthritis in rats by electroporation with interleukin-1 receptor antagonist. $J$ Biomed Sci Eng. 2016;9(7):323-336.
31. Cemazar M, Sersa G. Electrotransfer of therapeutic molecules into tissues. Curr Opin Mol Ther. 2007;9(6):554-562.

32. Feng S, Zhu L, Huang Z, et al. Controlled release of optimized electroporation enhances the transdermal efficiency of sinomenine hydrochloride for treating arthritis in vitro and in clinic. Drug Des Devel Ther. 2017;11:1737-1752.

33. Hagen M, Baker M. Skin penetration and tissue permeation after topical administration of diclofenac. Curr Med Res Opin. 2017;33(9): $1623-1634$.

34. Hansra P, Moran EL, Fornasier VL, Bogoch ER. Carrageenan-induced arthritis in the rat. Inflammation. 2000;24(2):141-155.

35. Cremasco V, Graham DB, Novack DV, Swat W, Faccio R. Vav/ phospholipase $\mathrm{C} \gamma 2$-mediated control of a neutrophil-dependent murine model of rheumatoid arthritis. Arthritis Rheum. 2008;58(9):2712-2722.

36. Smith E, McGettrick HM, Stone MA, et al. Duffy antigen receptor for chemokines and CXCL5 are essential for the recruitment of neutrophils in a multicellular model of rheumatoid arthritis synovium. Arthritis Rheum. 2008;58(7):1968-1973.

37. Springer TA. Traffic signals for lymphocyte recirculation and leukocyte emigration: the multistep paradigm. Cell. 1994;76(2):301-314.

38. Hartmann P, Erős G, Varga R, et al. Limb ischemia-reperfusion differentially affects the periosteal and synovial microcirculation. J Surg Res. 2012;178(1):216-222.

39. Hale LP, Martin ME, McCollum DE, et al. Immunohistologic analysis of the distribution of cell adhesion molecules within the inflammatory synovial microenvironment. Arthritis Rheum. 1989;32(1):22-30.

40. Gilroy DW, Colville-Nash PR, Willis D, Chivers J, Paul-Clark MJ, Willoughby DA. Inducible cyclooxygenase may have anti-inflammatory properties. Nat Med. 1999;5(6):621-622.

41. Scheja A, Forsgren A, Marsal L, Wollheim F. Inhibition of in vivo leucocyte migration by NSAIDs. Clin Exp Rheumatol. 1985;3(1): $53-58$.

42. Martinez LL, Oliveira MA, Miguel AS, et al. Enalapril interferes with the effect of diclofenac on leucocyte-endothelium interaction in hypertensive rats. J Cardiovasc Pharmacol. 2004;43(2):258-265.

43. Radhakrishnan R, Moore SA, Sluka KA. Unilateral carrageenan injection into muscle or joint induces chronic bilateral hyperalgesia in rats. Pain. 2003;104(3):567-577.

44. Sluka KA, Bailey K, Bogush J, Olson R, Ricketts A. Treatment with either high or low frequency TENS reduces the secondary hyperalgesia observed after injection of kaolin and carrageenan into the knee joint. Pain. 1998;77(1):97-102.

45. Skyba DA, Radhakrishnan R, Sluka KA. Characterization of a method for measuring primary hyperalgesia of deep somatic tissue. J Pain. 2005;6(1):41-47.

46. Hardy JD, Harold G, Goodell W, Goodell H. Experimental evidence on the nature of cutaneous hyperalgesia. J Clin Invest. 1950;29(1): $115-140$.

47. Lee TH, Wang CJ, Wu PC, Buerkle H, Lin SH, Yang LC. The thermal and mechanical anti-hyperalgesic effects of pre- versus post-intrathecal treatment with lamotrigine in a rat model of inflammatory pain. Life Sci. 2002;70(25):3039-3047.

48. Peter-Szabo M, Kekesi G, Nagy E, Sziver E, Benedek G, Horvath G. Quantitative characterization of a repeated acute joint inflammation model in rats. Clin Exp Pharmacol Physiol. 2007;34(5-6): 520-526.

49. Kennett EC, Davies MJ. Glycosaminoglycans are fragmented by hydroxyl, carbonate, and nitrogen dioxide radicals in a site-selective manner: implications for peroxynitrite-mediated damage at sites of inflammation. Free Radic Biol Med. 2009;47(4):389-400.

50. Blake DR, Winyard PG, Marok R. The contribution of hypoxiareperfusion injury to inflammatory synovitis: the influence of reactive oxygen intermediates on the transcriptional control of inflammation. Ann N Y Acad Sci. 1994;723:308-317.

51. Mapp PI, Grootveld MC, Blake DR. Hypoxia, oxidative stress and rheumatoid arthritis. Br Med Bull. 1995;51(2):419-436. 
52. Tak PP, Bresnihan B. The pathogenesis and prevention of joint damage in rheumatoid arthritis: advances from synovial biopsy and tissue analysis. Arthritis Rheum. 2000;43(12):2619-2633.

53. Saricaoglu F, Dal D, Salman AE, Doral MN, Kilinç K, Aypar U. Ketamine sedation during spinal anesthesia for arthroscopic knee surgery reduced the ischemia-reperfusion injury markers. Anesth Analg. 2005;101(3):904-909.
54. Hanachi N, Charef N, Baghiani A, et al. Comparison of xanthine oxidase levels in synovial fluid from patients with rheumatoid arthritis and other joint inflammations. Saudi Med J. 2009;30(11):1422-1425.

55. Bedard K, Krause KH. The NOX family of ROS-generating NADPH oxidases: physiology and pathophysiology. Physiol Rev. 2007;87(1): 245-313. 


\section{Supplementary materials}

\section{Characterization of the diclofenac sodium-containing hydrogel}

Rheological investigations and $\mathrm{pH}$ measurements were designed to characterize the hydrogel.

The $\mathrm{pH}$ of the semisolid formulations was measured with a Testo 206 pH meter (Testo SE \& Co. KGaA, Lenzkirch, Germany). The probe of the device was immersed into three different parts of the sample. The $\mathrm{pH}$ was adjusted to $8.0 \pm 0.1$.

The rheological properties were studied with a Physica MCR101 rheometer (Anton Paar, Graz, Austria). The measuring device was of the parallel plate type (with a $25 \mathrm{~mm}$ diameter and a gap height of $0.10 \mathrm{~mm}$ ). The flow and viscosity curve were recorded over the shear rate range from 0.1 to 100 and from 100 to $0.1 \mathrm{~s}^{-1}$ at $32^{\circ} \mathrm{C}$.

The flow curve of the gel can provide information on the viscosity changes under flow conditions and on the time dependency of the structure breakdown and recovery.

The flow curve of the gel presented shear thinning behavior, which means that the shear stress continuously increases with the shear rate, but the rate of the increase decreases. The curves showed slight thixotropy, which means the structure regeneration is time-dependent.

\section{High-performance liquid chromatography (HPLC) measurements of the synovial washing fluid and plasma samples}

The quantitative measurement of diclofenac sodium was carried out with the HPLC method.

\section{Chemicals and reagents for HPLC}

Methanol, orthophosphoric acid ( $85 \% \mathrm{v} / \mathrm{v})$, potassium dihydrogen phosphate, isopropanol, and n-hexane were bought from VWR International GmbH (Darmstadt, Germany). All reagents and solutions used were analytical grade, except the methanol, which was HPLC grade. The purified water for the HPLC was acquired from TKA Smart2Pure device (TKA, Burladingen, Germany).

\section{HPLC system and conditions}

The HPLC analysis of diclofenac sodium was conducted using an Agilent HPLC system (Agilent Technologies, Palo Alto, CA, USA) equipped with an automated solvent delivery system, which has an integrated degasser (1260 Infinity Quaternary Pump, Agilent Technologies), an Agilent
1260 Infinity autosampler, and a 1024-element diode array detector (1260 Infinity Diode Array Detector, Agilent Technologies). The system control and data acquisition were performed with Agilent ChemStation B.04.03 software (Agilent Technologies). The chromatographic parameters are provided in Table S1.

The chromatographic separations were performed on Kromasil $^{\circledR} 100$ 5C188 (250×4, 6 mm ID, $5 \mu$ m) (Phenomenex Inc., Torrance, CA, USA) analytical column. The column temperature was maintained at a constant $35^{\circ} \mathrm{C}$. Separations were performed in gradient mode. The mobile phase was eluted at a flow rate of $1.5 \mathrm{~mL} \mathrm{~min}^{-1}$, and effluent was monitored at $254 \mathrm{~nm}$.

The mobile phase consisted of two components. Component $\mathrm{A}$ was a mixture of methanol and PBS buffer at a ratio of 80:20 volume/volume percentage (potassium hydrogen phosphate, $5 \mathrm{mM}$ and diluted orthophosphoric acid buffer, $5 \mathrm{mM}, \mathrm{pH} 2.5$, adjusted by adding $85 \%$ orthophosphoric acid). Component B was a 20:80 (v/v) mixture of methanol and PBS buffer.

The preliminary ratio was 30:70 (v/v) A:B for $1 \mathrm{~min}$; then the volume for B was increased from $70 \%$ to $100 \%$ after $4.1 \mathrm{~min}$ and sustained for $1 \mathrm{~min}$ before being returned to the initial conditions after $5 \mathrm{~min}$. After a measurement, $2 \mathrm{~min}$ at 154 bar pressure for equilibration of the column was performed before the next injection. The retention time for diclofenac sodium was $4.5 \pm 0.054 \mathrm{~min}$ (relative standard deviation $=0.29 \%$ ) (Table S1).

\section{Preparation of standard solutions and calibration samples}

A stock solution of diclofenac sodium $(1,000 \mu \mathrm{g} / \mathrm{mL})$ was prepared in a 50:50 (v/v) mixture of methanol and HPLC water. External standard calibration solutions were prepared by dilution of the stock solution with the $50: 50(\mathrm{v} / \mathrm{v})$ mixture of methanol and HPLC water to produce solutions with

Table SI Parameters of the chromatographic measurement

\begin{tabular}{|c|c|}
\hline Mobile phase & Mixture of methanol and PBS buffer \\
\hline $\mathrm{pH}$ & 2.5 \\
\hline Flow rate & $\mathrm{I} \mathrm{mL} / \mathrm{min}$ \\
\hline Injection volume & $20 \mu \mathrm{L}$ \\
\hline Elution type & Gradient elution \\
\hline Detection wavelength & $254 \mathrm{~nm}$ \\
\hline Column & Kromasil $1005 \mathrm{Cl} 8,5 \mu \mathrm{m} \mathrm{250 \times 4.6 \textrm {mm }}$ \\
\hline Temperature & $35^{\circ} \mathrm{C}$ \\
\hline Evaluation & External standard calibration, 6 conc $(n=3)$ \\
\hline Time & $20 \mathrm{~min}$ \\
\hline
\end{tabular}

Abbreviation: conc, concentrations. 
concentrations of 0 (as blank), 10, 20, 50, 100, and $150 \mu \mathrm{g} / \mathrm{mL}$ (six standard solutions).

\section{Sample extraction procedure}

An aliquot of plasma $(1 \mathrm{~mL})$ was combined with $100 \mu \mathrm{L}$ of the internal standard solution (added amount $1.25 \mu \mathrm{g}$ ). The sample was acidified by adding $2 \mathrm{~mL}$ of $0.83 \mathrm{M}$ phosphoric acid and $4 \mathrm{~mL}$ of hexane isopropyl alcohol (90:10). The mixtures were shaken for $10 \mathrm{~min}$ on a rotating shaker at $250 \mathrm{rpm}$ and then centrifuged at $1,500 \mathrm{~g}$ for $10 \mathrm{~min}$. The aqueous phase was frozen, and the organic phase was transferred to another tube and evaporated to dryness with nitrogen gas at room temperature. The dried residue was reconstituted with $300 \mu \mathrm{L}$ of mobile phase and shaken for $15 \mathrm{~s}$ on a vortex mixer, and then a $20 \mu \mathrm{L}$ aliquot was injected into the HPLC system.

An aliquot of $1.2 \mathrm{~mL}$ of synovial fluid was added to $2 \mathrm{~mL}$ of orthophosphoric acid $(0.83 \mathrm{M})$ and $0.6 \mathrm{~mL}$ of isopropyl alcohol and vortexed for a few seconds. After that, $5.4 \mathrm{~mL}$ of $n$-hexane was added, and the mixture was centrifuged at $9,000 \mathrm{~g}$ for $5 \mathrm{~min}$. The organic phase was transferred to a clean tube, and the solvent was evaporated to dryness with nitrogen gas at $30^{\circ} \mathrm{C}$. The residue was dissolved in $1.2 \mathrm{~mL}$ of the mobile phase by vortexing. An aliquot of $20 \mu \mathrm{L}$ was injected into the chromatograph.

\section{Linearity}

Linearity was studied by preparing standard solutions in the range of $0-150 \mu \mathrm{g} \mathrm{mL}^{-1}(\mathrm{n}=6)$, plotting a graph of concentration against area under the curve and determining the linearity. Two methods (the short and long methods) were compared to choose the optimal one for the HPLC analysis (Table S2).

Based on the linearity test and the low relative standard deviation \% values, the short method is recommended. The advantage is a runtime shortened by 42\% (35-20 min; Figure S2).

Table S2 Comparison of the parameters of the long and short methods

\begin{tabular}{lll}
\hline Parameters of the HPLC method & Long method & Short method \\
\hline Linear regression equation & $y=20.491 x-7.4762$ & $Y=20.338 x-1.9623$ \\
Coefficient of determination & $R^{2}=0.9999$ & $R^{2}=0.9999$ \\
Number of samples & $\mathrm{n}=15$ & $\mathrm{n}=15$ \\
Runtime (min) & 35 & 20 \\
RTDs (min), mean \pm standard deviation & $18.721 \pm 0.054$ & $14.610 \pm 0.002$ \\
RSD - RTDs (\%) & 0.29 & 0.02 \\
RSD - AUC (\%) & 1.70 & 1.52 \\
RSD - maximum limit (\%) & 2.00 & 2.00
\end{tabular}

Abbreviations: AUC, area under the curve; HPLC, high-performance liquid chromatography; RSD, relative standard deviation; RTDs, residence time distributions. 
A

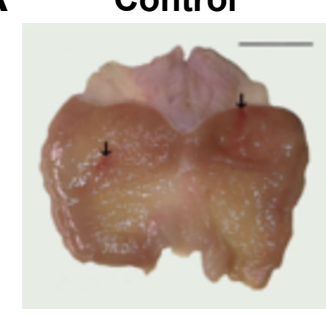

EP

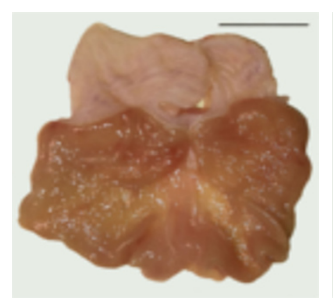

Per os

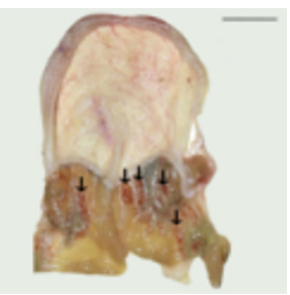

Topical

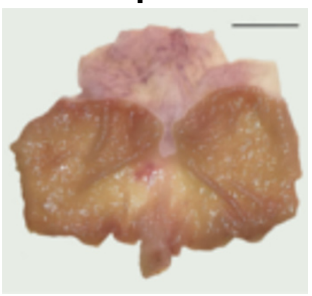

B

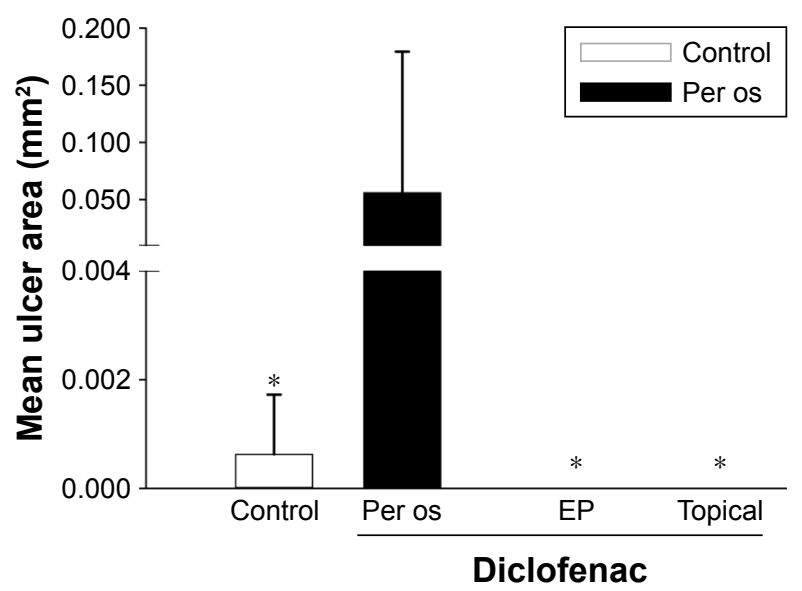

Figure SI Gastric adverse effects of diclofenac intake.

Notes: The effects of diclofenac treatment on the gastric mucosa. (A) Diclofenac treatment-induced gastric adverse effects. Scale bars represent 10 mm. Black arrows show edema, irritation, and petechia formation. (B) Mean area of gastric lesions. The white column represents the control group (per os saline-treated), and the black column represents the per os diclofenac-treated group. The pale and dark columns (not visible, as values are 0.000 ) represent the topical and EP-combined topical diclofenac-treated groups, respectively. Data are presented as means $\pm \mathrm{SD}$. ${ }^{*} p<0.05$ vs per os diclofenac-treated group (Kruskal-Wallis one-way analysis and Dunnet test).

Abbreviations: EP, electroporation; SD, standard deviation of the mean.

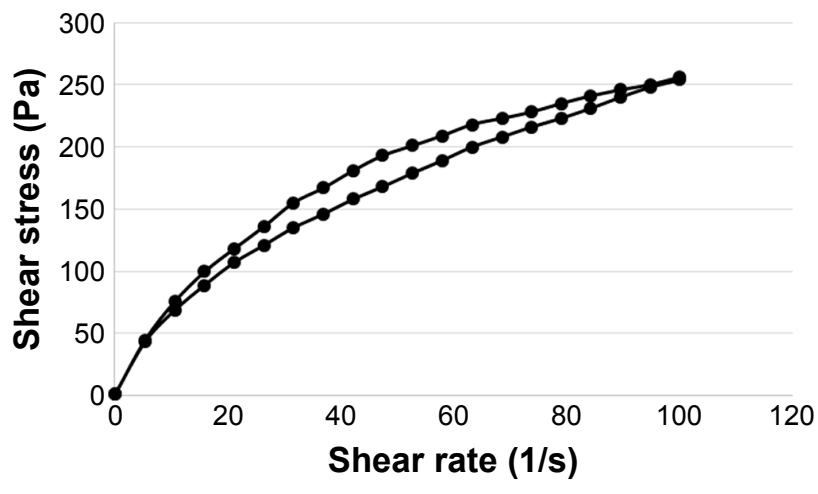

Figure S2 The flow curve of the diclofenac sodium-containing hydrogel.

\section{Publish your work in this journal}

Drug Design, Development and Therapy is an international, peerreviewed open-access journal that spans the spectrum of drug design and development through to clinical applications. Clinical outcomes, patient safety, and programs for the development and effective, safe, and sustained use of medicines are the features of the journal, which has also been accepted for indexing on PubMed Central. The manuscript management system is completely online and includes a very quick and fair peer-review system, which is all easy to use. Visit http://www.dovepress.com/testimonials.php to read real quotes from published authors. 